\title{
PLANTAS DANINHAS COM POSSIBILIDADES DE FORRAGEIRAS PARA BOVINOS EM CONDIÇÕES DE CERRADO.
}

\author{
M. BRANDÃO FERREIRA*, G.A.R. MACEDO* \& J.P. LACA BUENDIA* \\ * Pesquisadores da Empresa de Pesquisa \\ Agro-pecuária de Minas Gera is - \\ EP AMIG - C. Postal $515-30.000$ - Belo \\ Horizonte - MG. Trabalho ap resentado no \\ 31. Congresso Nacional de Botânica, \\ em Il he us /I ta buna, B A, 1980.
}

\section{RESUMO}

Os autores apresentam algumas considerações sobre 34 espécies de plantas daninhas, cujos fragmentos foram encontrados no material retirado, através de fístulas esofágicas, de novilhos azebuados, sob regime de pastoreio intensivo, em pastagem nativa de cerrado na Fazenda Santa Rita - Prudente de Moraes — EPAMIG — Minas Gerais.

Unitermos: plantas daninhas, forrageiras, bovinos, cerrados.

\section{SUMMARY}

This paper presents some considerations about 34 weeds utilized by fistulated zebu calves grazing intensively on a cerrado native pasture at the Fazenda Santa Rita — Prudente de Moraes EPAMIG - MG.

Two hours after ingestion, materials were sampled trough out the animals esophagial fistula and plant fragments were identified by stereoscope.

Keywords: weeds, forage, cattle, cerrado native pasture.

\section{INTRODUÇÃO}

O levantamento de plant as danin has no Estado de Minas Gerais, em pastagens e culturas várias, tem sido o objetivo de inúmeros trabalhos $(4,5,6,8)$, justificando pois, o interesse dos autores que, no presente trabalho, pretendem reconsiderar o conceito de "planta daninha", em termos de pastagens, aplicado às espécies enfocadas. As referidas espécies são consideradas plantas daninhas por diversos autores $(1,2,4,5,7,8,9,11$, 12).

Inúmeros têm sido os trabalhos sobre pastagens nativas de cerrado, apresentando a proporção ocorrente entre gramíneas e plantas de folhas largas, selecionadas por bovinos fistulados $(16,20)$, assim como o consumo e digestibilidade (10). Os resultados permitiram concluir que no período da seca as plantas daninhas e arbustos têm participação importante na dieta. Os dados de evolução do peso vivo foram razoáveis, em função da lotação utilizada, para esse tipo de pastagem $(0,6$ UA/ha, sendo 1 unidade animal $/$ ha $=400$ $\mathrm{kg}$ de peso vivo ). Na mesma área utilizada para os trabalhos acima citados $(10,16$, 20) as ervas, arbustos e árvores tiveram uma participação de $17 \%$ de média anual na dieta dos bovinos tendo o seu maior pico em agosto (32\%), isto para a primeira etapa ( julho de 1977 a julho de 1978). Na segunda etapa (julho de 1978 a julho de 1979), a participação foi menor em termos de média, atingindo entretanto $47 \%$ e $69^{\circ} \%$ o em setembro e outubro, respectivamente. A participação em menor escala nos demais meses deve-se à baixa precipitação, o que vem a explicar essa menor incidência das folhas largas em virtude da maior permanência das gramíneas, especialmente do Paspalum notatum Fülgge, na pastagem $(14,15)$.

O pres ente trabalho teve como objetivo a identificação botânica das plantas daninhas de cerrado visando conscienti- 
zar os pecuaristas da importância desse material, que é sempre desc artado quando da limpeza das pastagens naturais, no sentido de preservá-lo e utilizá-lo.

\section{MATERIAIS E MÉTODOS}

O estudo foi realizado na Fazenda Experimental de Santa Rita, Prudente de Moraes - MG, pertencente à Empresa de Pesquis a Agro pecuária de Minas Gerais - EPAMIG, no período de julho de 1977 a julho de 1979. A área está situada na Zona Metalúrgica de Minas Gerais, nas coordenadas $19^{\circ} 28^{\prime}$ de latitude sul e $40^{\circ} 15^{\prime}$ de longitude oeste de Green wich e uma altitude de $732 \mathrm{~m}$, acima do nível do mar.

O clima característico da região é do tipo Cwa, da classificação de Köppen, considerado como temperado chuvoso (mesotérmico) em que a temperatura do mês mais frio é inferior a $18^{\circ} \mathrm{C}$ e a do mês mais quente superior a $22^{\circ} \mathrm{C}$. Os verões são quentes e chuvosos e os invernos frescos e secos. A temperatura média do ar (anual) da região é de $20,6^{\circ} \mathrm{C}$ e a precipitação média anual de é de $1403 \mathrm{~mm}$; a temperatura média das máximas é de $27,9^{\circ} \mathrm{C}$.

Os solos da área acham-se representados, na sua grande maioria, por Latossolo Vermelho Amarelo, ocorrendo pequenas inclusões de Latossolo Vermelho Escuro, ambos distróficos de textura argilosa. São solos profundos, porosos e apresentam grande estabilidade de agregados. Sua estrutra é do tipo granular pequena e muito pequena, com aspecto maciço sendo muito bem drenados. Sua gênese está relacionada com um processo de intemperização intensa, resultando da lavagem de silicas e bases com a concentração relativa de sesquióxidos. A argila predominante é a caulinita (17).

A formação vegetal que recobre a faze nda tem como tôn ica o cerrado. A área apresenta estrato arbóreo que varia entre 4-8 metros de altura, de densidade bastante variável, conforme a posição que ocupa no relevo (suave ondulado) sendo o estrato arbustivo, subarbustivo e herbáceo bem represen tativo. Nas partes mais altas as árvores mostram-se mais densas, decaindo de porte nos declives que margeiam o córrego Caieiras, córrego este que deli mita de um dos lados, a área em estudo.

Entre as árvores são frequentes as espécies: Qualea grandiflora Mart., Qualea parviflora Mart., Eugenia dysenterica DC., Diospyros hispida DC., Styrax camporum, Annona crassif lora Mart., Astronium frax in ifolium Schott, Bowdichia virgilioides H.B.K., Byrsonina coc-colobifolia (spr.), Kut eByrsonima verbascifolia Juss., Caryocar brasiliense Camb., Copaifera langsdorfii Desf., Couepia grandiflora Benth., Dalbergia violacea (Vog) Malme., Didymopanax macrocarpum (Cham. \& Schl.) Seem., Dimorphandra mollis Benth., Emmotum nitens (Benth.) Miers., Hymenaea stigonocarpa Mart., Lafoensia pacari St. Hil., Machaerium opacum Vog., Magonia pubescens St. Hil., Piptadenia communis Benth., Pisonia tomentosa Casar., Stryphnodendron barbatimao Mart., Tabebuia caraiba (Mart.) Bur., Tabebuia ochracea Cham., Terminalia fagifolia Mart. \& Zucc., Xylopia aromatica (Lam.) Mart., entre outras. O estrato arbustivo mostra-se bastante rico, se ndo as es pécies ma is frequentes : Banisteriopsis clausseniana (Juss.) And. Gates, Campomanesia pubescens Berg., Campomanesia coerulea Berg., Cremastrus sceptrum (Chaco.) Bur., Erythroxylum campestre St. Hil., Erythroxylum tortuosum Mart., Bauhinia bongardi Steud., Brosimum gaudichaudii Tréc., Peritassa campestris Walp., Myrcia rufipes DC., Myrcia variabilis DC., Zeyhera digitalis (Veil.) Hoehne Cochlospermum regium (Mart.) Pilger, entre outras. Estrato subarbustivo e herbáceo muito variado sendo bastan te fre quente o Paspalum notatum Flügge.

Inúmeras plantas daninhas mesclam se à vegetação nativa, a saber o "picão", as "malvas", o "fumo-bravo", os "camarás", as "hortelãs", o "anil", a "fruta de lobo", o "gervão", os "ass a-peix es", entre outras, que levadas pelos animais e pelo homem, ali se instalaram e se multiplicaram com o decorrer dos anos. A pastagem não sofre controle de qualquer natureza, sendo mantida baixa pelo consumo dos arbustos e ervas pelos animais, assim como, pelo pisoteio destes. 
A área utilizada foi de 40 ha com 36 animais, sob regime de pastoreio contínuo, sendo oito com fístulas esofágicas. Uma vez ao mês, durante uma semana (se gunda do mês ), os animais eram levados pela manhã ao curral para a retirada dos tampões e colocação das bolsas coletoras e, com posterior acesso às áreas de pastejo durante uma hora e meia. Em seguida, eram recolhidos ao curral para se efe tuar a retirada das bolsas, cujo material era armazenado em congelador para posterior análise botânica.

Da soma das amostras diárias de cada animal fistulado, retirava-se uma amostra compost a por animal, por semana. As amostras eram armazenadas em congelador, até a sua utilização, para determinação de sua composição botânica. Antes da análise, procedia-se ao descongelamento e lavagem deste material para remoção da saliva. Foi empregado para análise botânica, o método de pontos micros cópi cos descritos por Hark er et al. (13), utiliztado por Medina (16) e Simão Neto (20) para este tipo de pastagem. Os fragmentos não identificados foram retirados da bandeja, onde se faziam as observações, com o auxílio de uma pinça e colocados em frascos, contendo uma solução da FAA. Em seguida, eram etiquetados e enviados ao Laboratório de Botânica da EPAMIG, Belo Horizonte, para posterior identificação de espécies.

$\mathrm{Na}$ identifi cação das espé cies o trabalho foi feito em duas etapas, a saber: campo e laboratório.

No campo foram feitas coletas de exsicatas das plantas existentes na área estudada durante praticamente 4 anos (1974, 1976, 1977, 1978) atendendo aos trabalhos : 1 - Levantamento feito por Silva et. al. (19) em área adjacente, cujo material botânico devidamente identificado, acha-se guardado no Herbário da EPAMIG (PAMG) ; 2 - Material coletado na área do experimento e também guardado no PAMG, usado como subsídios para caracterização da área e, cuja listagem, consta do trabalho de Simão Neto (20) ; 3 - Determinação de freqüên- cia, densidade e abundância de espécies do cerrado, na mesma área de 40 ha, utilizada para o trabalho em questão, tam bém inclusas do PAMG (4) ; Coletas de exsicatas, julho de 1977 a julho de 1978, para o trabalho da Dieta de Bovinos em Pastagem Nativa de Cerrado $(14,15)$. Praticamente, a área foi int ens ame nte coletada durante esses quatro anos.

No laboratório, de cada exsicata devidamente identificada foi retirada uma folha adulta a qual foi examinada detalhadamente em seus aspectos morfológicos externos e, posteriormente, parcialmente macerada em solução hidróxido de sódio a $3 \%$, lavada, submetida à secagem natural e fixada entre 2 folhas de "filme" transparente para projeção (3M do Brasil Ltda.) quando então foram agrupadas de acordo com alguns caracteres morfológicos mais evidentes, como : pilosidade (presença ou ausência); tipo de venação (segundo Ettinghausen in Felipe e Alencastro) (3) ; glândulas (presença ou ausência) ; tipo de bordas, ápices e bases, entre outros caracteres, constituindo macro-fichas de fácil manuseio.

Para facilitar a identificação das espécies, foram elaboradas chaves especiais baseadas nos carcteres acima mencionados que figuram como itens básicos, separando-se as espécies por uma série de pequenos detalhes morfológicos, conseguidos quando do exame detalhado da folha de cada espécie, antes de sua maceração. Em seguida foram examinados os fragmentos recolhidos do material obtido através de fístulas esofágicas e, separados segundo o método de pontos microscópicos descrito por Harker et. al. (13), utilizando-se estereoscópios "ZEISS", as chaves e as macrofichas.

Os resultados obtidos foram lançados em fichas preenchendo os seguintes dados : nome da espécie, nome popular, local, n. ${ }^{\circ}$ do bovino (que ao ser fistulado recebe um número seriado a partir de 01 (um), o que vem a explicar os números bastante diversificados que os bovinos utilizados vão apresentar); tipo de fragmentos obtidos, observações extras 
No item "Tipos de fragmentos", foram observados alguns sub-itens a saber : folhas (inteiras ou fragmentos), frutos (int eiros, frag ment os, sementes), flor es e infl ores cênc ias. Não foram considerados os fragmentos de caules.

Considerou-se o sub-item "inteiras" em folhas, pois muitas vezes, plantas de folhas simples mas, de pequeno tamanho ou folíolos, podem aparecer inteiros nas amostras, o mesmo ocorrendo com os de frutos. Consideraram-se flores e inflorescências como dois itens separados pois, muit as vezes inflorescências inteiras podiam ser observadas, como por exemplo aquelas de espécies do gênero Waltheria.

\section{RESULTADOS E DISCUSSÃO}

As plantas consideradas daninhas encontram-se nos quadros 1 e 2 .

Na primeira etapa do trabalho, de julho de 1977 a julho de 1978, foram coletadas cerca de 2.112 elementos retirados do material oriundo das fístulas esofáficas dos bovinos. Entre os 2.112, 665 pertenciam a plantas tidas como daninhas o que corresponde a pouco mais de $32^{\circ} \%$ o do total de elementos recolhidos.

Na segunda etapa, de julho de 1978 e julho de 1979, foram identificados cerca de 2.178 elementos. Entre os 2.178, 675 pertenciam a plantas daninhas, correspondendo a $31 \%$ dos elementos recolhidos.

$\mathrm{O}$ restante des ses element os pertence a 45 famílias representadas por 82 gên eros pró prios do cerrado, con ten do 118 espécies, selecionadas pelos bovinos fistulados em sua dieta.

$\mathrm{Na}$ área em questão, foram coletadas cerca de 300 espécies nativas distintas, até o presente momento.

No primeiro período, praticamente $10 \%$ dos elementos identificados correspondiam a fragmentos de frutos (205) e folhas (10) de Solanum lycocarpum St. Hil, planta bastante comum em nossos cerrados $(7,18,21)$, mas tida como da- ninha por outros autores $(4,5,8)$. Esses elementos foram encontrados nas amostras de todo o período e selecionados por todos os bovinos. O fruto é realmente visado pelos animais pois, os fragmentos de folhas encontrados, provavelmente, foram comidos ao acaso, pois a percentagem é extremamente baixa. Ferreira, et. al. (6) não mencionaram a espécie como sendo a que entre os arbustos ocorresse em maior abundância, frequência e densidade na área, ficando os primeiros lugares para Bauhinia bongardi Steud (com $70 \%$ de frequência; 7,6 de densidade e 9,1 de abundância) e Serjanea gracilis Radlk, (com 67\% de frequência ; 6,4 de densidade e 9,6 de abundância), seguidos de inúmeras outras espécies. Tais dados confirmam essa seletividade bovina, mencionada por muitos dos autores citados.

Desmodium canum é a segunda colocada com 3,7\% apresentando 78 fragmentos ; segundo os autores acima mencionados a espécie ocupa no quadro 1 (estrato herbáceo - arbustivo) o terceiro lugar, sendo a lista encabeçada por Paspalum notatum com $83 \%, 19,3$ e $23,1 \%$ respectivamente de frequência, densidade e abundância. E planta também mencionada como pertencente à flora dos cerrados e dos campos mas, tida também como daninha, pelos mesmos autores acima relacionados.

A terceira espécie que alcança valores mais altos é Portulaca oleracea L., ruderal típica, com 68 fragmentos de folhas, correspondendo a $3,2 \%$ dos frag mentos; seguida de Sida rhombifolia, com 2,4\%, também daninha, bastante conhecida.

As demais espécies alcançam percentagens menores, entre $1,04 \%$ e $0,62 \%$, a saber : Sida cordifolia, Waltheria indica, Melochia pyramidata, Desmodium adscendens, Desmodium barbatum, Cassia flexuosa, Lantana nivea, Stachytarphetta cayennensis.

A família Leguminosae apresentou cerca de $32 \%$ de espécies entre aquelas selecionadas.

No segundo período é ainda Solanum 
Quadro 1 - Espécies das Plantas Daninhas, cujos fragmentos foram coletados através das Fístulas Esofágicas em Bovinos, em Pastagem Nativa de Cerrado, no periodo de julho de 1977 a julho de 1978 - Fazenda Santa Rita, Prudente de Moraes - MG.

\begin{tabular}{|c|c|c|c|c|c|c|c|c|c|c|}
\hline \multirow{2}{*}{ Espécies } & \multirow{2}{*}{ Familia } & \multirow{2}{*}{\multicolumn{2}{|c|}{\begin{tabular}{|c|} 
Folhas \\
Int. Frag. \\
\end{tabular}}} & \multirow{2}{*}{\multicolumn{2}{|c|}{\begin{tabular}{c|} 
Frutos \\
Int. Frag.
\end{tabular}}} & \multicolumn{2}{|c|}{ Flores } & \multirow{2}{*}{ Total } & \multirow{2}{*}{$\begin{array}{c}\begin{array}{c}\text { Números } \\
\text { de } \\
\text { Bovinos }\end{array} \\
\end{array}$} & \multirow{2}{*}{$\begin{array}{l}\text { Percenta- } \\
\text { gem }\end{array}$} \\
\hline & & & & & & Sem.| I & Int. & & & \\
\hline $\begin{array}{l}\text { Acanthospermum australe } \\
\text { Bidens pilosa } \\
\text { Cordia verbenacea } \\
\text { Cassia rotundifolia } \\
\text { Cassia flexuosa } \\
\text { Cassia bauhinifolia } \\
\text { Commelina nudiflora } \\
\text { Corchorus hirtus } \\
\text { Crotalaria anagyroides } \\
\text { Desmodium adscendens } \\
\text { Desmodium canum } \\
\text { Desmodium barbatum } \\
\text { Desmodium purpureum } \\
\text { Desmodium uncinatum } \\
\text { Dioidia teres } \\
\text { Elephanthopus mollis } \\
\text { Emilia sonchifolia } \\
\text { Hyptis carpinifolia } \\
\text { Hyptis lophantha } \\
\text { Hydrocotyle umbetlata } \\
\text { Indigofera truxillensis } \\
\text { Lantana lilacina } \\
\text { Lantana nivea } \\
\text { Leonotis nepetaefolia } \\
\text { Melochia pyramidata } \\
\text { Portulaca oleracea } \\
\text { Rhynchosia minima } \\
\text { Sida cordiofolia } \\
\text { Sida rhombifolia } \\
\text { Solanum tycocarpum } \\
\text { Stachytarphetta cayennensis } \\
\text { Taraxacum officinale } \\
\text { Vernonia ferruginea } \\
\text { Vernonia polyanthes } \\
\text { Waltheria indica }\end{array}$ & $\begin{array}{l}\text { Compositae } \\
\text { Compositae } \\
\text { Boraginaceae } \\
\text { Leguminosae } \\
\text { Leguminosae } \\
\text { Leguminosae } \\
\text { Commelinaceae } \\
\text { Tiliaceae } \\
\text { Leguminosae } \\
\text { Leguminosae } \\
\text { Leguminosae } \\
\text { Leguminosae } \\
\text { Leguminosae } \\
\text { Leguminosae } \\
\text { Rubiaceae } \\
\text { Compositae } \\
\text { Compositae } \\
\text { Labiatae } \\
\text { Labiatae } \\
\text { Umbelliferae } \\
\text { Leguminosae } \\
\text { Verbenaceae } \\
\text { Verbenaceae } \\
\text { Labiatae } \\
\text { Sterculiaceae } \\
\text { Portulacaceae } \\
\text { Leguminosae } \\
\text { Malvaceae } \\
\text { Malvaceae } \\
\text { Solanaceae } \\
\text { Verbenaceae } \\
\text { Compositae } \\
\text { Compositae } \\
\text { Compositae } \\
\text { Sterculiaceae }\end{array}$ & $\begin{array}{r}3 \\
2 \\
4 \\
8 \\
6 \\
3 \\
1 \\
2 \\
2 \\
11 \\
61 \\
9 \\
4 \\
1 \\
1 \\
1 \\
2 \\
2 \\
2 \\
1 \\
2 \\
6 \\
1 \\
7 \\
9 \\
2 \\
7 \\
38 \\
4 \\
1 \\
3 \\
4 \\
4\end{array}$ & $\begin{array}{r}2 \\
6 \\
2 \\
2 \\
6 \\
2 \\
2 \\
3 \\
2 \\
5 \\
17 \\
6 \\
3 \\
1 \\
1 \\
6 \\
2 \\
4 \\
4 \\
1 \\
4 \\
6 \\
3 \\
13 \\
59 \\
2 \\
15 \\
4 \\
10 \\
9 \\
1 \\
4 \\
4 \\
8\end{array}$ & $\begin{array}{l}1 \\
1\end{array}$ & 205 & 3 & 9 & $\begin{array}{r}5 \\
8 \\
6 \\
10 \\
12 \\
5 \\
3 \\
5 \\
5 \\
17 \\
78 \\
15 \\
7 \\
2 \\
2 \\
7 \\
4 \\
6 \\
6 \\
2 \\
4 \\
6 \\
12 \\
4 \\
20 \\
68 \\
5 \\
22 \\
51 \\
215 \\
13 \\
2 \\
7 \\
8 \\
21\end{array}$ & \begin{tabular}{|l|}
04 \\
702,707 \\
702 \\
705,707 \\
718 \\
702 \\
703,718 \\
$44,707,705$ \\
$04,718,702$ \\
04 \\
$04,06,702,703$ \\
$06,703,718$ \\
44 \\
44,703 \\
702,718 \\
718,707 \\
44,718 \\
707,705 \\
705,707 \\
702,718 \\
04 \\
04 \\
$04,06,703,718$ \\
04,06 \\
$06,44,702,705,707$ \\
Todos \\
04 \\
$44,702,705,718$ \\
$04,06,705,718$ \\
Todos \\
$04,702,707$ \\
718 \\
04 \\
$702,703,707$ \\
$705,707,04,702$
\end{tabular} & $\begin{array}{r}0,24 \\
0,38 \\
0,28 \\
0,47 \\
0,57 \\
0,24 \\
0,14 \\
0,24 \\
0,24 \\
0,80 \\
3,69 \\
0,71 \\
0,33 \\
0,09 \\
0,09 \\
0,33 \\
0,19 \\
0,28 \\
0,28 \\
0,09 \\
0,19 \\
0,28 \\
0,57 \\
0,19 \\
0,95 \\
3,22 \\
0,24 \\
1,04 \\
2,41 \\
10,18 \\
0,62 \\
0,09 \\
0,33 \\
0,38 \\
0,99 \\
\end{array}$ \\
\hline Fragmentos de Plantas Daninhas & & & & & & & & 655 & & \\
\hline Total dos fragmentos encontrados & & & - & & & & & 2112 & & \\
\hline
\end{tabular}


Quadro 2 - Espécies das Plantas Daninhas encontradas nos fragmentos coletados através de Fístulas Esofágicas em Bovinos, em Pastagem Nativa de Cerrado, no período de julho de 1978 - julho de 1979 - Faz. Santa Rita, Prudente de Moraes - MG.

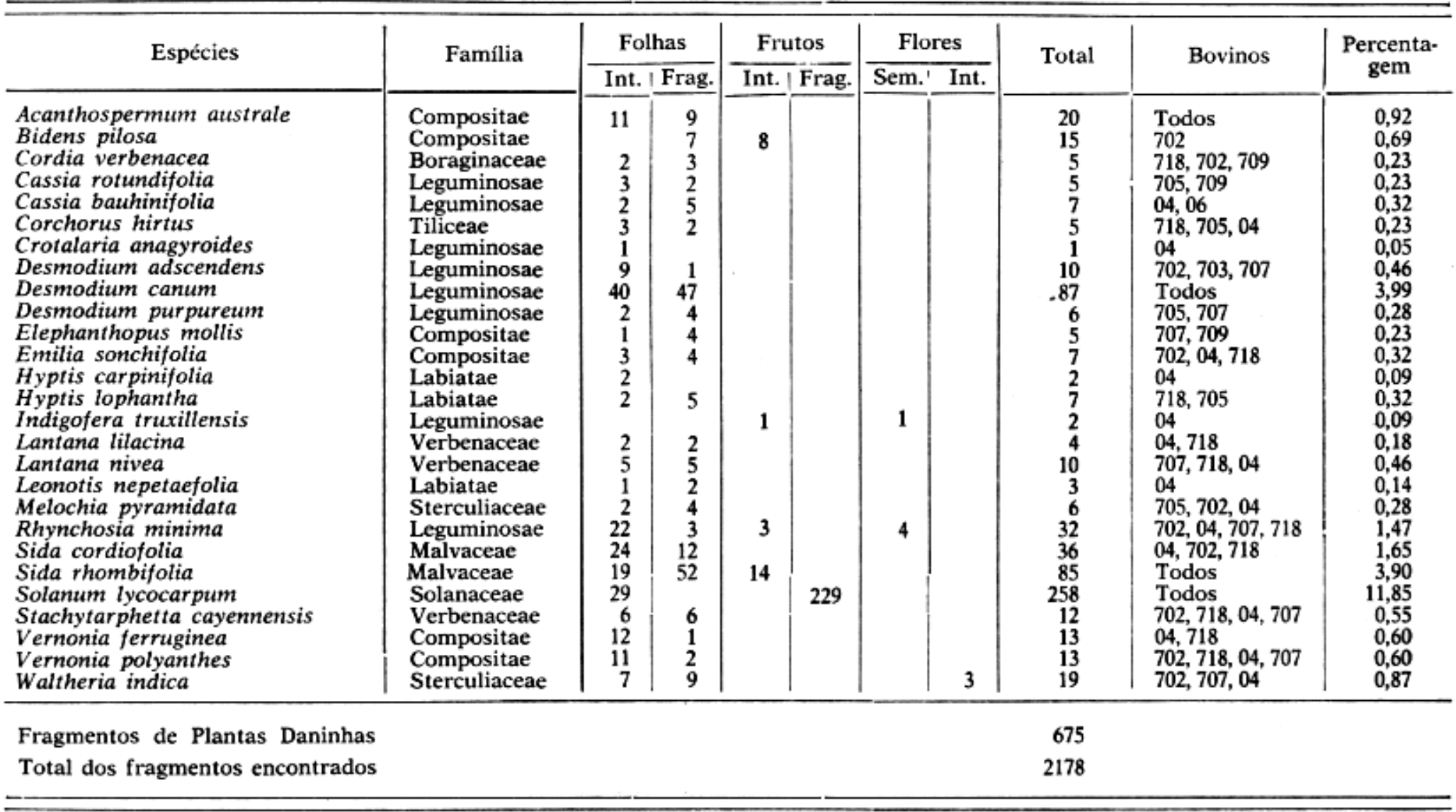


lycocarpum a espécie mais representativa com $12 \%$ o ( 225 fragmentos de frutos e 29 de folhas), seguida de Desmodium canum com 4\% (87 fragmentos de folhas) e de Sida rhombifolia com $4 \%$ (85 fragmentos de fol has e frutos), sendo as trề s espécies selecionadas durante todo o ano, por todos os bovinos.

Sida cordifolia e Rhynchosia mínima apresentaram 1,6\% e 1,5\% não tendo a segunda espécie constada da 1 etapa. As demais apresentaram valores entre $1 \%$ e 0,5\% como: Acanthospermum australe, Waltheria indica, Bidens pilosa, Vernonia polyanthes, Vernonia ferrugina e Stachytarphet ta cayennensis.

No quadro 3 são apresentados os valores de frequência, densidade e abundância das espécies coletadas na mesma área, dados esses tirados do trabalho de Ferreira, et. al. (6 ), estando as espécies daninhas orden adas segundo o seu grau de participação na dieta, com exceção de algumas que não constaram do referido trabalho. Foram consideradas somente aquelas que tiveram percentagem acima de $0,5 \%$.

\section{LITERATURA CITADA}

1. Blanco, H.G. Catálago das espécies de mato infestantes de areas cultivadas no Brasil. Gramíneas (anuais e perenes), Compostas Malvaceas, Leguminosas, Solanaceas (Coletânea artigos do "O Biológico"), CATI, Campinas, 1978.

2. Cardenas, I. Reyes, C.E. \& Doll. J.D. Tropical weeds 1: ed. Bogotá, Lybrary of Congress, 1972, $335 \mathrm{pg}$. ils.

3. Felipe, G.M. \& Alencastro, F.M.M. Estudo da nervação das compositae do Cerrado I - Anais da Av. Bras. Cienc. Rio de Janeiro. 38: 127-157, 1966.

4. Ferreira, M.B. \& Laca-Buendia, J.P. del C. Levantamento $\mathrm{e}$ análise qualitativa de plantas invasoras ocorrentes em culturas na área da Fazenda Experimental de Santa Rita - EPAMIG - Anais da Soc. Bot. do Brasil, Cong. Nac. de Batânica, 28:, p. 219-226, 1977.

5. Ferreira, M.B. \& Laca-Buendia, J.P. del C. Invasoras de Pastagens do Estado de Minas Gerais. Publ. avulsas EPAMIG, Belo Horizonte, 56 p. il 1976 (a).
6. Ferreira, M.B.. O. Laca-Buendia, J.P. del C. \& Macedo, G.A. de R. Frequência, densidade $\mathrm{e}$ abundância de espécies de cerrado $\mathrm{x}$ Latossolo vermelho amarelo na Fazenda Santa Rita - EPAMIG. Prudente de Morais, M.G. In: Congresso Nacional de Botânica, 30.' Campo Grande, 1979. Resumos.

7. Ferri, M.G. Plantas do Brasil - Especies do Cerrado, 1.* ed. S. Paulo, Ed. Edgard Blücher Ltda. e Ed. USP. 1962. 239 p. il.

8. Laca-Buendia, J.P. del C.; Ferreira, M.B. \& Gavilanes, M.L. Levantamento das ervas daninhas nas primeiras regiōes algodoeiras do Estado de Minas Gerais. Relatório Projeto Algodão 1974/75. EPAMIG/ESAL/ UFMG/UFV - Belo Horizonte. 103-120. s.d.n. 1977.

9. Leitão Filho, H.F.; Aranha, C. \& Bacchi, O. Plantas invasoras de culturas no Estado de São Paulo. São Paulo, HUCITEC, 1972, V.1. V. 2 .

10. Lima, M.A. Consumo e digestibilidade da forragem selecionada por bovinos em área de cerrado. Belo Horizonte. Escola de Veterinária da UFMG. 1976. 193 p. (tese MS).

11. Lorenzi, H.J. Principais ervas daninhas do Estado do Paraná. Bol. Técnico do IAPAR. Londrina - Fundação Instituto Agronômico do Paraná (2) 204 p. julho. 1976.

12. Gentchujnicov I.D. Chave artificial para identificação de plantas daninhas do Estado de São Paulo. São Paulo. 1966/1968. 305 p. il.

13. Harker, K.W.; Torrel, O.T. \& San Dyne, G.M. Botanical examination of forage from esophageal fistula in cattle, J. Anim. 23 (4): 465-1964.

14. Macedo, G.A. de R., Ferreira, M.B. \& Escuder, C.J. Dieta de novilhos em pastagens nativa de cerrado I. Publ. avulsa EPAMIG. Belo Horizonte. $1978-27$ p. il.

15. Macedo, G.A. de R. Ferreira, M.B. \& Escuder, C.J. Dieta de novilhos em pastagens nativa de cerrado. II. Arquivo da Escola de Veterinária da UFMG. Belo Horizonte, 1979 (no prelo).

16. Medina, A.R. Composição botânica e qualidade da dieta selecionada em pastagem nativa por novilhos azebuados com fistulas esofágicas, I. Periodo de março a agosto de 1975. Belo Horizonte. Esc. de Veterinária da UFMG, 1976, 84p. (tese MS).

17. Mota, P.E.F. da - Levantamento dos solos da Fazenda Experimental Santa Rita - 
EPAMIG, Município de Prudente de Morais, 1980. (no prelo).

18. Rizzini, C.T. - A flora do cerrado - análise florística das savanas centrais. In "Simpósio sobre o cerrado". Coord. de M. G. Ferri. Ed. Edgard Blücher Ltda. e Ed. USP - São Paulo - 105-154, 1971.

19. Silva, J.B.; Ferreira, M.B. \& Avelar, B.C. Contribuiçăo ao conhecimento da vegetaçāo de campo cerrado de Sete Lagoas -
Minas Gerais. Oréades. Belo Horizonte V (7.9); 92-117, 1974/76.

20. Simão Neto, M. Composição botânica $e$ qualidade da dieta selecionada por novi thos azebuados com fístulas esofágicas II Período de setembro a fevereiro de 1976 Belo Horizonte. Esc. de Veterinária de UFMG. 1976. 64p. (tese MS).

21. Wraming, E. Lagoa Santa. Traduçăo de Al bert Loefgren. Imprensa Ofícial. Belo Ho rizonte. 1980 . 282p. il.

Quadro 3 - Valores de Frequência, Densidade e Abundância de Algumas Espécies de Plantas Daninhas do Cerrado - Fazenda Santa Rita, Prudente de Moraes - MG.

\begin{tabular}{l|c|c|c|c}
\hline \multicolumn{1}{c|}{ Espécies } & $\begin{array}{c}\text { Total de } \\
\text { Fragmentos } \\
\text { Encontrados }\end{array}$ & Frequência & Densidade & Abundância \\
\hline Solanum tycocarpum & 473 & 10 & 0,3 & 2,7 \\
Desmodium canum & 165 & 53 & 3,5 & 6,6 \\
Sida rhombifolia & 136 & 43 & 1,7 & 4,0 \\
Sida cordifolia & 58 & 13 & 0,7 & 5,0 \\
Waltheria indica & 40 & 10 & 0,2 & 1,7 \\
Stachytarpheta cayennensis & 25 & 13 & 0,3 & 2,0 \\
Acanthospermum australe & 25 & 12 & 0,3 & 2,2 \\
Bidens pilosa & 23 & 3 & 0,3 & 1,0 \\
Vernonia polyanthes & 21 & 40 & 3,3 & 8,2 \\
Cassia rotundifolia & 15 & 17 & 0,2 & 1,4 \\
Desmodium barbatum & 15 & 10 & 0,6 & 5,7 \\
Cassia flexuosa & 12 & 7 & 0,1 & 1,3 \\
\hline \hline
\end{tabular}

OBS:: Os resultados referem-se aos existentes no trabalho de Ferreira, Laca-Buendia \& Macedc (1979). 